\title{
Characterization of the $\beta$-barrel assembly machine accessory lipoproteins from Borrelia burgdorferi
}

\author{
Joshua P Dunn, Melisha R Kenedy, Henna Iqbal and Darrin R Akins*
}

\begin{abstract}
Background: Like all diderm bacteria studied to date, Borrelia burgdorferi possesses a $\beta$-barrel assembly machine (BAM) complex. The bacterial BAM complexes characterized thus far consist of an essential integral outer membrane protein designated BamA and one or more accessory proteins. The accessory proteins are typically lipid-modified proteins anchored to the inner leaflet of the outer membrane through their lipid moieties. We previously identified and characterized the B. burgdorferi BamA protein in detail and more recently identified two lipoproteins encoded by open reading frames bb0324 and bb0028 that associate with the borrelial BamA protein. The role(s) of the BAM accessory lipoproteins in B. burgdorferi is currently unknown.

Results: Structural modeling of B. burgdorferi BB0028 revealed a distinct $\beta$-propeller fold similar to the known structure for the E. coli BAM accessory lipoprotein BamB. Additionally, the structural model for BB0324 was highly similar to the known structure of BamD, which is consistent with the prior finding that BB0324 contains tetratricopeptide repeat regions similar to other BamD orthologs. Consistent with BB0028 and BB0324 being BAM accessory lipoproteins, mutants lacking expression of each protein were found to exhibit altered membrane permeability and enhanced sensitivity to various antimicrobials. Additionally, BB0028 mutants also exhibited significantly impaired in vitro growth. Finally, immunoprecipitation experiments revealed that BB0028 and BB0324 each interact specifically and independently with BamA to form the BAM complex in B. burgdorferi.

Conclusions: Combined structural studies, functional assays, and co-immunoprecipitation experiments confirmed that BB0028 and BB0324 are the respective BamB and BamD orthologs in B. burgdorferi, and are important in membrane integrity and/or outer membrane protein localization. The borrelial BamB and BamD proteins both interact specifically and independently with BamA to form a tripartite BAM complex in B. burgdorferi. A working model has been developed to further analyze outer membrane biogenesis and outer membrane protein transport in this pathogenic spirochete.
\end{abstract}

Keywords: Borrelia burgdorferi, Lyme disease, BAM complex, Lipoproteins, BamA, BamB, BamD

\section{Background}

The pathogenic spirochetes Borrelia burgdorferi, B. garinii, and B. afzelii are the etiologic agents of Lyme disease [1-3]. Although B. burgdorferi possesses both a cytoplasmic and outer membrane (OM) similar to Gram-negative bacteria, its OM differs significantly from the typical Gramnegative $\mathrm{OM}$ in that it lacks the immunogenic glycolipid lipopolysaccharide [4]. Instead, the borrelial OM contains an abundant number of outer surface lipoproteins, which have been designated Osps [5-23]. The Osps are soluble

\footnotetext{
*Correspondence: darrin-akins@ouhsc.edu

Department of Microbiology and Immunology, University of Oklahoma

Health Sciences Center, Oklahoma City, OK 73104, USA
}

proteins that are anchored to the bacterial surface by their lipid moiety [6]. In addition to the numerous Osps, the borrelial OM also contains integral outer membrane proteins (OMPs) that contain membrane-spanning domains composed of antiparallel, amphipathic $\beta$-strands $[23,24]$. Presently, only ten OMPs have been identified in B. burgdorferi [22,25-33]. However, freeze-fracture electron microscopy studies have revealed that there are numerous OMPs present in the borrelial OM [24]. Therefore, it is likely that the ten known OMPs only represent a small subset and many have likely not yet been identified. Identification and characterization of novel 
OMPs from B. burgdorferi has become an important goal in the field because they may represent novel vaccine candidates.

Exactly how OMPs are folded and inserted into the $\mathrm{OM}$ of bacteria is an active area of research [34-43]. While it has been shown that bacterial OMPs (e.g., OmpA, PagP, OmpX, FadL, OmpLA) can spontaneously fold into their native conformation and incorporate into synthetic lipid bilayers and/or detergent micelles in vitro [44-47], recent studies have revealed that the lipid composition of bacterial OMs does not readily allow for spontaneous insertion of most OMPs [39]. To overcome this kinetic barrier of insertion in vivo, bacteria require the $\beta$-barrel assembly machine (BAM) complex [39]. The BAM complex is composed of an essential BamA protein and one or more accessory proteins [34,48-51]. BamA is an OMP itself that contains an N-terminal periplasmic region with five polypeptide transport-associated (POTRA) domains. POTRA domains are all composed of a highly similar $\beta-\alpha-\alpha-\beta-\beta$ structural motif $[35,36]$ and are important for the interaction between BamA and BAM accessory lipoproteins [52,53]. In E. coli, there are four BAM complex accessory lipoproteins: BamB, $\mathrm{C}, \mathrm{D}$, and $\mathrm{E}$. BamB and BamD specifically interact with the BamA POTRA domains, while BamC and BamE associate with the larger complex by interacting with BamD [48-50,54,55]. All BAM complexes characterized to date have been shown to be essential for bacterial survival [56-58] due to the critical role they play in OM biogenesis and OMP transport $[51,59,60]$.

While all BAM complexes contain a BamA protein, the accessory lipoproteins can vary greatly in number and overall sequence among different bacterial groups $[49,51,53,61-65]$. For instance, most $\beta$ - and $\gamma$-proteobacteria typically possess four accessory proteins: BamB, C, $\mathrm{D}$, and $\mathrm{E}[50,63,66]$. In contrast, only BamD orthologs have been identified thus far in the $\delta$ - and $\varepsilon$-proteobacteria [49]. We previously reported that the BAM complex in B. burgdorferi is comprised of a BamA ortholog and two putative lipoproteins designated BB0324 and BB0028, with BB0324 being suggested to be a BamD ortholog $[25,67]$. To further these prior analyses, we have used structural studies, functional assays, and co-immunoprecipitation experiments to generate a refined topological model of the B. burgdorferi BamA protein and to examine the roles of BB0028 and BB0324 in the borrelial BAM complex. The combined studies revealed that BB0028 and BB0324 play a role in membrane integrity and/or OMP localization, which is consistent with BB0028 and BB0324 being BamB and BamD orthologs, respectively. A working model is proposed for the borrelial BAM complex that can now be used to further explore OM biogenesis and OMP transport in this pathogenic spirochete.

\section{Results}

Structural model of the B. burgdorferi BamA protein

The $B$. burgdorferi $\beta$-barrel assembly machine (BAM) complex appears to be comprised of three proteins: the integral outer membrane protein (OMP) BamA and two accessory lipoproteins designated BB0028 and BamD/ BB0324 [25,67]. While there is little information regarding the structure or function of the borrelial accessory lipoproteins, the BamA protein was previously examined using two different structural modeling algorithms to predict the topology of the membrane-spanning C-terminal domain and the conformation of the $\mathrm{N}$-terminal periplasmic region [25]. The recently determined crystal structure of $N$. gonorrhoeae BamA [36], however, provided a known template to refine the structural prediction of the borrelial BamA protein using the I-TASSER protein structure prediction algorithm [68-70]. As shown in Figure 1A, the model predicted for B. burgdorferi BamA was observed to be highly similar to $N$. gonorrhoeae BamA, and the confidence score (C-score) for the predicted model was 0.55. The $\mathrm{C}$-score is the most pertinent score for assessing model quality and can range from -5 to +2 , with scores $>-1.5$ considered to accurately indicate the final secondary structure conformation [70]. The I-TASSER server also provides a template modeling score (TM-score) to assess the overall structural similarity between the predicted model and the known template structure (TMscore $>0.5$ indicates correct topology prediction). The TM-score for the borrelial BamA model was $0.79 \pm 0.09$. Combined, the $\mathrm{C}$-score and TM-score indicate that the newly-refined model generated for B. burgdorferi BamA is of high quality.

The modeled structure depicted in Figure 1A (left) indicates that $B$. burgdorferi BamA consists of a $\mathrm{N}$ terminal periplasmic domain containing five polypeptide transport-associated (POTRA) motifs followed by a $\beta$-barrel domain with 16 membrane-spanning $\beta$-strands. A conserved $\alpha$-helical region was identified in extracellular loop four, which has also been noted in all BamA structures characterized to date [35,36]. Additionally, loop six contains an arginine-glycine-tryptophan triad that may correspond to the RGF motif found in the same loop of other BamA proteins, which has been shown to be essential for BamA function [43,71-73] (Figure 1B). To further examine the reliability of the model generated, we next inserted a c-Myc tag into predicted extracellular loop three (Figure 1B; c-Myc insert shown in green). As shown in Figure $1 \mathrm{C}$, surface immunofluorescence assays using c-Myc-specific antibodies verified that the c-Myc tag, as predicted, was located on the borrelial surface, which is entirely consistent with the structural model predicted by I-TASSER. As expected, the wildtype strain lacking a c-Myc tag displayed no reactivity with the c-Myc antibodies. To ensure that the fragile outer membrane of 


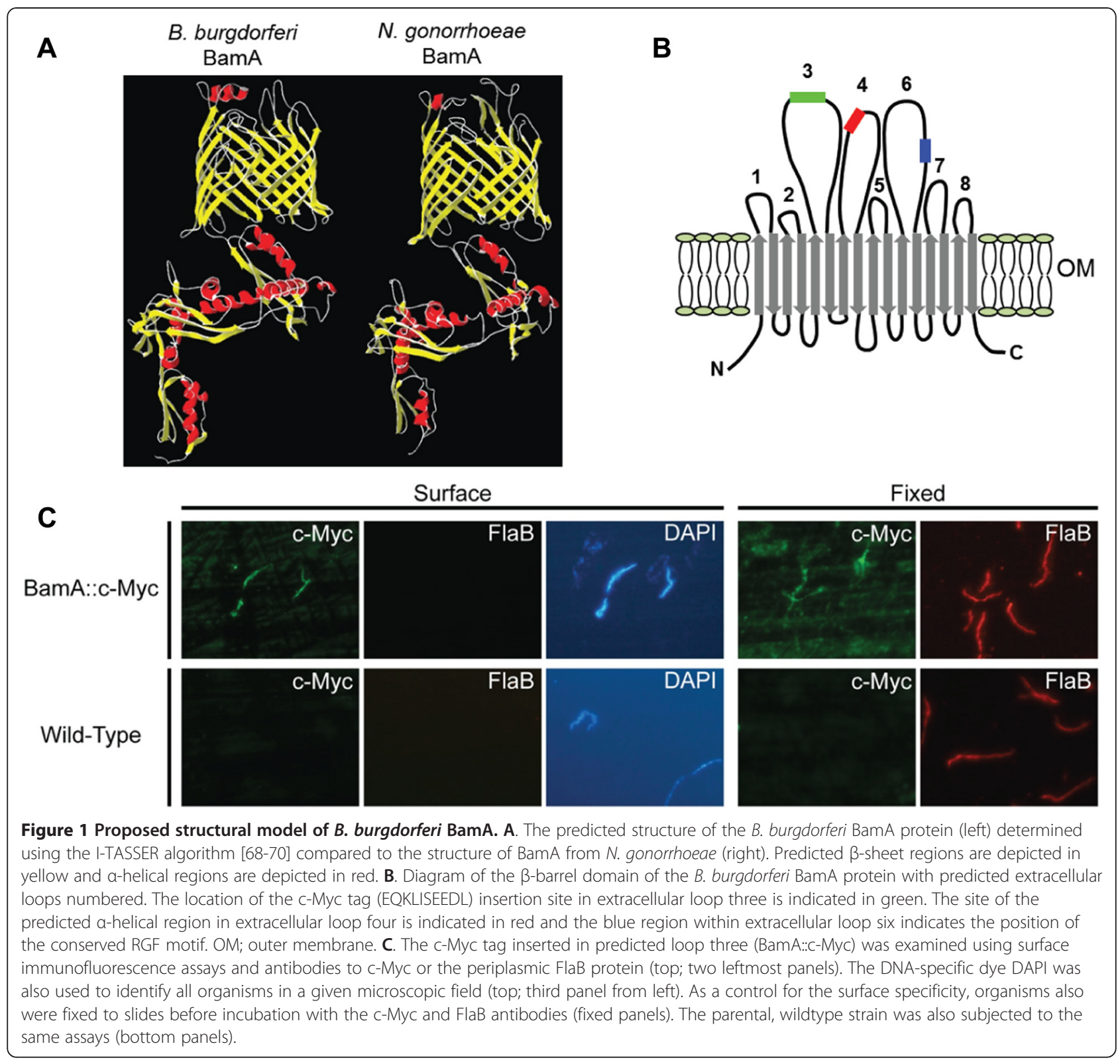

B. burgdorferi was not disrupted, antibodies specific for the periplasmic FlaB protein were also included in the surface localization experiments. When anti-FlaB antibodies were co-incubated with the anti-cMyc antibodies, no FlaB was identified, indicating that the outer membranes were intact (Figure $1 \mathrm{C}$; panels second from left). The DNA-binding dye DAPI was also included in the mounting media for all immunofluorescence experiments to help identify all spirochetes in a given microscopic field. As a control for FlaB reactivity, organisms also were dried to slides and fixed with acetone to disrupt the outer membranes before co-incubation with the FlaB and c-Myc antibodies, as shown in the rightmost panels of Figure 1C. As expected, the fixed organisms fluoresced brightly with the FlaB antibodies.

\section{Structural models of the $B$. burgdorferi BAM accessory lipoproteins}

The B. burgdorferi BamA protein has been shown to coimmunoprecipitate with two accessory lipoproteins, encoded by open reading frames bb0028 and bb0324 [67]. BB0324 was previously shown to share significant similarity with the $\mathrm{N}$-terminus of BamD from $N$. meningitidis and to contain tetratricopeptide repeat (TPR) domains. TPR domains are antiparallel $\alpha$-helices commonly involved 
in mediating protein-protein interactions [74]. The sequence similarity between BB0324 and other known BamD proteins suggested BB0324 is a putative BamD ortholog [67]. BB0028, however, shares no sequence similarity with any of the known or putative BAM accessory proteins. When the I-TASSER algorithm [68-70] was used to model BamD/BB0324 without a specified template, the structure predicted consisted of five stacked $\alpha$-helical domains (Figure 2A; left). This predicted structure was highly similar to the $\mathrm{N}$-terminal region of the known E. coli BamD structure [75,76] (Figure 2A; right). BB0028 was predicted by I-TASSER to fold into a $\beta$-propeller structure (Figure 2B; left), which is the known conformation of the E. coli BamB protein [52,55,77] (Figure 2B; right).
Generation of B. burgdorferi BamD/BB0324 and BB0028 mutants

While prior co-immunoprecipitation experiments [67] combined with the structural modeling outlined above suggest BamD/BB0324 and BB0028 are members of the borrelial BAM complex, neither of these approaches provided empirical evidence that they are functional components of the BAM complex in B. burgdorferi. Therefore, to determine if BamD/BB0324 and/or BB0028 function as would be expected of BAM complex accessory proteins, we generated BamD/BB0324 and BB0028 mutants as described in the Methods section. As shown in Figure 3A, bamD/bb0324 was deleted and replaced by a streptomycin resistance cassette using homologous recombination. The

\section{$\begin{array}{ccc}\text { A } & \text { B. Burgdorferi } & \text { E. coli } \\ \text { BamD/BB0324 } & \text { BamD }\end{array}$}
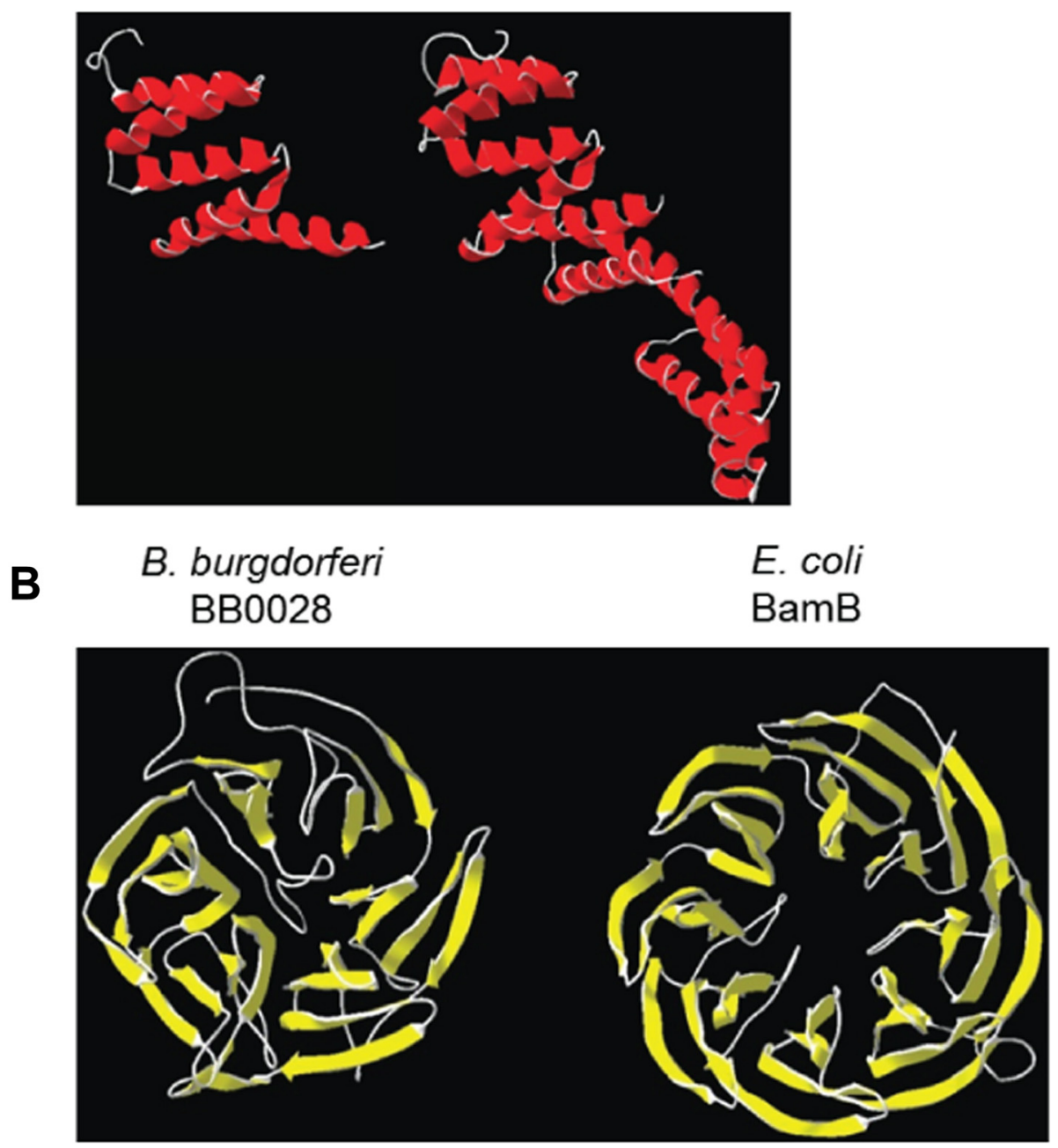

Figure 2 Structural models of BamD/BB0324 and BB0028. Structural modeling using the I-TASSER algorithm with predicted $\beta$-sheet regions shown in yellow and a-helical regions shown in red. A. Predicted structure of B. burgdorferi BamD/BB0324 (left) compared to the known structure of the E. coli BamD protein (right). B. Predicted structure of B. burgdorferi BB0028 (left) compared to the known structure of the E. coli BamB protein (right). 


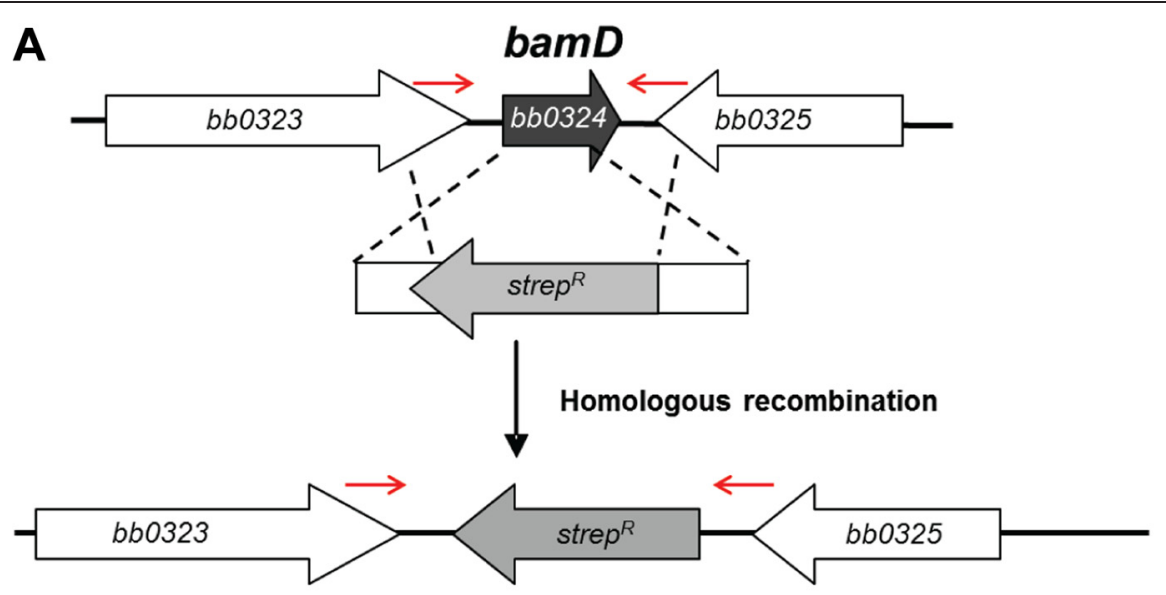

B

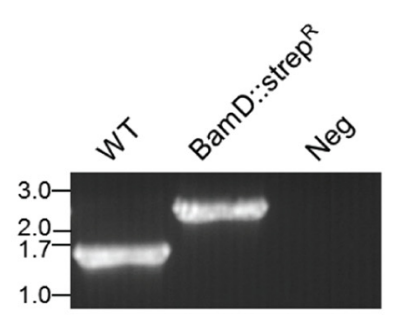

C

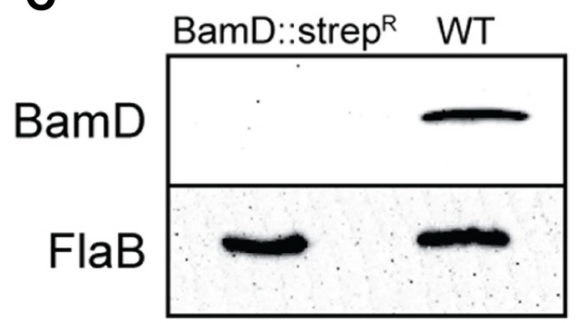

Figure 3 Generation of a bamD/bb0324 mutant. A. A bamD/bb0324 mutant was generated through homologous recombination by replacing the bamD/bb0324 gene with a streptomycin resistance cassette. Red arrows indicate primers used to confirm insertion of the streptomycin cassette in the borrelial genome. B. PCR amplification resulted in a $1.4 \mathrm{~kb}$ amplicon in the wildtype strain while the BamD/BB0324 mutant containing the streptomycin cassette produced a $2.4 \mathrm{~kb}$ amplicon, as expected. A PCR reaction with no DNA template (Neg) was included as a negative control. DNA sizes, in kilobase pairs, are indicated at left. C. Whole-cell lysate from the BamD/BB0324 mutant (BamD::strep $\left.{ }^{R}\right)$ and parental (WT) strains were subjected to immunoblot analysis using BamD/BB0324 specific antibodies (top panel). FlaB antisera was used to ensure equal loading of lysates examined (bottom panel).

presence of the streptomycin resistance cassette was confirmed by PCR analyses using primers flanking bamD/ bb0324 (Figure 3B). Immunoblot with BamD/BB0324 specific antisera confirmed that the BamD mutant strain, designated BamD::strep ${ }^{\mathrm{R}}$, did not express BamD, as expected (Figure 3C). Numerous attempts to delete bb0028 through homologous recombination were unsuccessful, which suggested BB0028 may be essential for in vitro cultivation of B. burgdorferi. To overcome this potential caveat, we generated an IPTG-regulatable mutant of BB0028 by expressing the native $b b 0028$ gene under control of the IPTG-inducible flacp promoter (Figure 4A). The resulting strain was confirmed by PCR to contain the streptomycin resistance cassette/flacp promoter construct (Figure $4 \mathrm{~B}$ ), and regulation of BB0028 by IPTG was confirmed by immunoblot analysis using polyclonal, monospecific rat anti-BB0028 antibodies (Figure 4C).

Interestingly, the BB0028 regulatable mutant was observed to replicate in vitro without addition of IPTG in the growth media (Figure 4C), although it should be noted that the organisms were qualitatively less motile when examined under the microscope and replicated at a much slower rate as compared to wildtype organisms expressing normal amounts of BB0028. This observation suggested that BB0028, while not absolutely essential for in vitro cultivation of the organism, may be relevant to the overall growth and physiology of B. burgdorferi. To more quantitatively examine these observations, we next examined the growth rate of the BB0028 mutant in vitro, which revealed that the doubling time of the mutant was $14 \mathrm{~h}$, while the parental strain had a doubling time of only $8 \mathrm{~h}$. The BB0028 mutant also required 72-96 hours longer to reach stationary phase as compared to the wildtype parental strain (Figure 5A). To ensure that the ability of the BB0028 mutant to grow in the absence of IPTG was not the result of a secondary mutation in the lacI gene or flacp promoter that allowed the mutant to express BB0028, we performed immunoblot analyses which confirmed that BB0028 was not expressed in the mutant strain during cultivation (Figure 5A; inset). When similar growth curve analyses were performed on the BamD/ BB0324 mutant strain, no impact on the rate of in vitro growth was observed as compared with the parental strain (Figure 5B). 


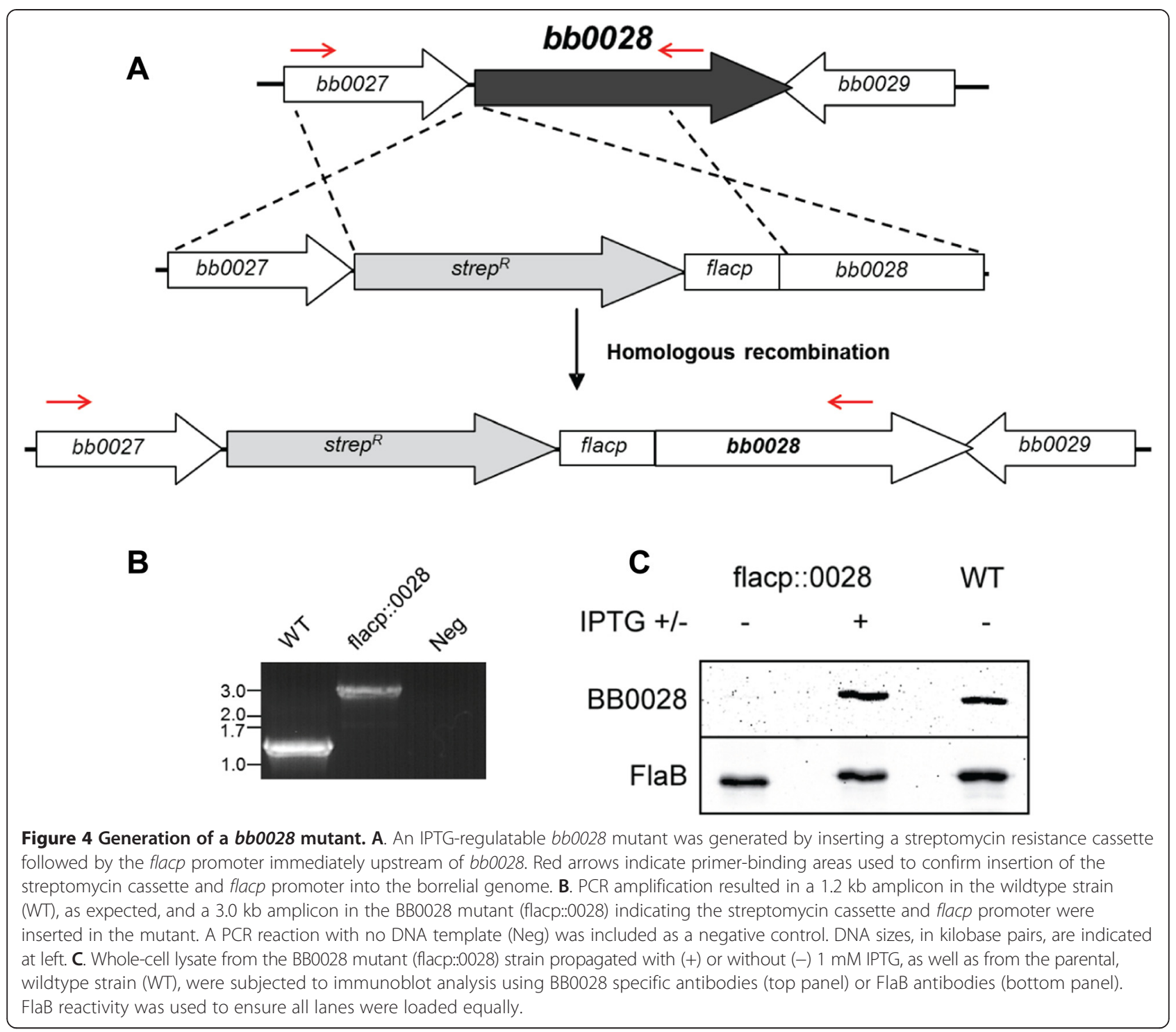

Loss of BB0028 or BamD/BB0324 enhances antimicrobial sensitivity

In Gram-negative bacteria, mutants lacking various BAM accessory proteins have altered outer membrane (OM) permeability and sensitivity profiles to antimicrobials $[64,78,79]$. Therefore, we examined whether the absence of the B. burgdorferi BAM accessory proteins BB0028 or BamD/BB0324 affected susceptibility to antimicrobial agents. To determine the minimum inhibitory concentration of specific antimicrobials, the respective parental wildtype and mutant strains were cultivated in media containing varying concentrations of carbenicillin, cefotaxime, tetracycline, or minocycline. As shown in Table 1, when compared to the wildtype B31-A3-LK strain, the susceptibility of the BB0028 mutant (flacp::BB0028) to carbenicillin increased by two-fold, and susceptibility to tetracycline increased by four-fold. The BamD/BB0324 mutant (BamD::strep ${ }^{\mathrm{R}}$ ) also exhibited altered susceptibility; it was observed to be two-fold and eight-fold more susceptible to tetracycline and minocycline, respectively, as compared to the parental B31-5A4NP1 strain. We also examined the susceptibility profile of the B. burgdorferi IPTG-regulatable BamA mutant [25] as a control. Reducing BamA expression using limiting amounts of IPTG in the regulatable BamA mutant (flacp::BamA) resulted in increased susceptibility to all antibiotics tested, as expected, with a four-fold increase in susceptibility to carbenicillin and two-fold increases to cefotaxime, tetracycline, and minocycline, as compared to the parental strain B31A3-LK. Taken together, these results suggest that both BB0028 and BamD/BB0324 play important, although possibly different, roles in OM composition and/or integrity. 

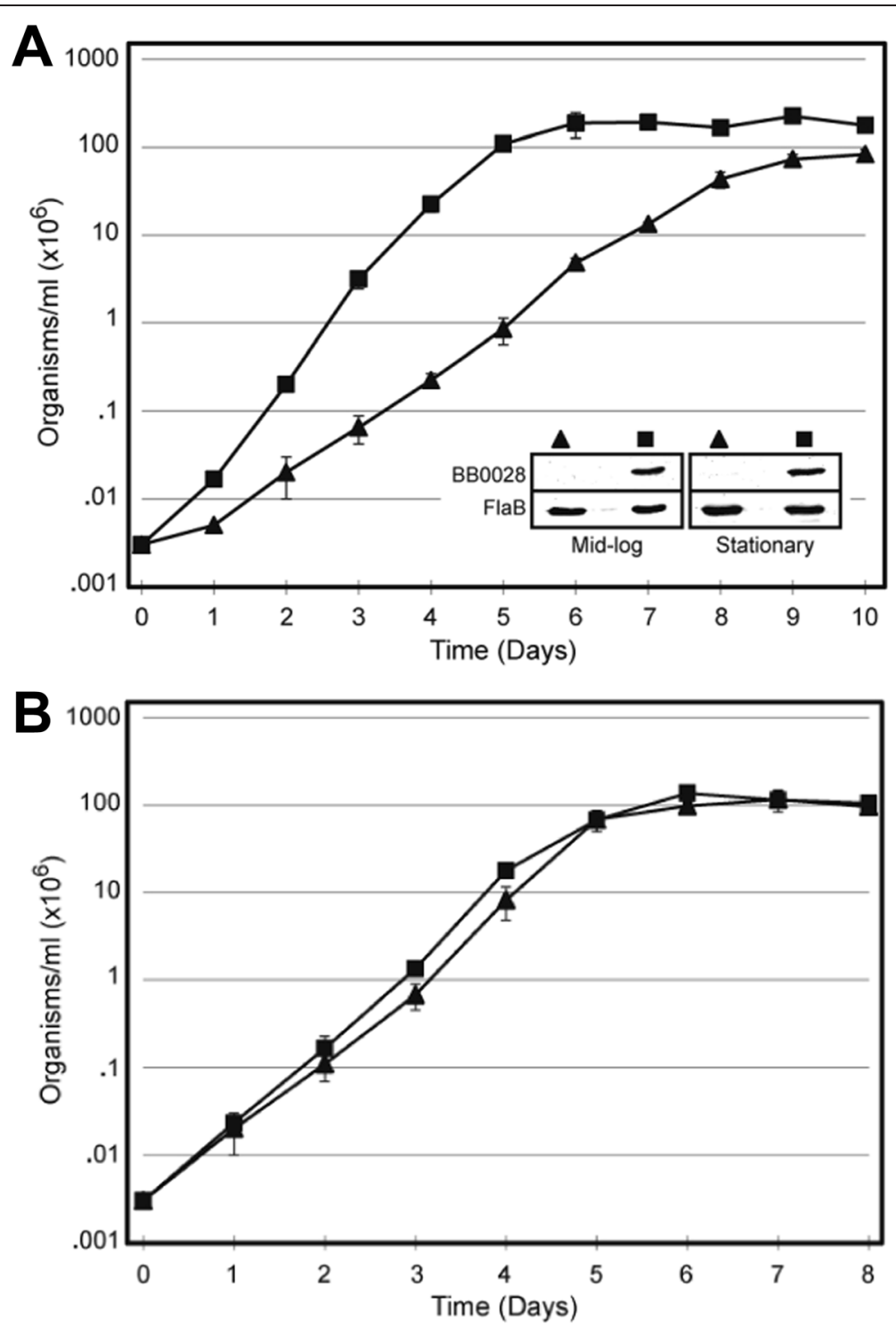

Figure 5 The BB0028 mutant exhibits impaired growth in vitro. A. Growth rate analysis of the parental strain (- and BB0028 mutant strain $(\boldsymbol{\Delta})$. The BB0028 mutant required 3-4 more days to reach stationary phase than the parental strain. The inset confirms by immunoblot that BB0028 was not expressed by the BB0028 mutant ( $\mathbf{\Delta})$ during culture. As a control, the wildtype, parental strain ( $\mathbf{\square})$ was also immunoblotted for BB0028. Lysates also were probed with FlaB specific antibodies to confirm equivalent loading. B. Growth rate comparison of the wildtype (汭) and BamD/BB0324 mutant $(\boldsymbol{\Delta})$ strains.

\section{Export of BesC into the outer membrane is diminished in the BB0028 mutant}

To examine the underlying causes for the enhanced susceptibility of the different mutants to antimicrobial agents, we next examined whether the presence of the OMP BesC was altered in the OM of the BB0028 or BamD/BB0324 mutant strains. BesC is the outer membrane protein component of a known B. burgdorferi multidrug efflux complex that is involved in enhancing resistance to various antimicrobials [27]. We therefore performed immunoblot analysis on isolated OM fractions to examine the level of BesC exported into the OM of the BB0028 and BamD/BB0324 mutant strains. Interestingly, when equal amounts of the isolated OM fractions were compared, there was a marked decrease in the amount of BesC located in the OM of the BB0028 mutant as compared to its parental wildtype strain (Figure 6A; BesC OM panels). By contrast, no observable decrease in $\mathrm{BesC}$ was detected in the $\mathrm{OM}$ fraction of the BamD mutant strain as compared to its wildtype parental strain (Figure 6B; BesC OM panels). The overall expression of BesC and its export to the inner membrane also did not 
Table 1 Absence of BamA, BB0028, or BamD/BB0324 affects antimicrobial sensitivity

\begin{tabular}{|c|c|c|c|c|}
\hline & \multicolumn{4}{|c|}{$\begin{array}{l}\text { Minimum inhibitory concentration }(\mathrm{ng} / \mathrm{ml})^{a} \\
\text { (Fold change susceptibility) }^{b}\end{array}$} \\
\hline & Carbenicillin & Cefotaxime & Tetracycline & Minocycline \\
\hline flacp::BB0028c & $156(2 X)$ & 20 & $78(4 X)$ & 78 \\
\hline BamD::strep ${ }^{R}$ & 313 & 39 & $39(2 X)$ & $10(8 X)$ \\
\hline flacp::BamA ${ }^{d}$ & $78(4 X)$ & $10(2 X)$ & $156(2 X)$ & $39(2 X)$ \\
\hline B31-A3-LK & 313 & 20 & 313 & 78 \\
\hline B31-5A4NP1 & 313 & 39 & 78 & 78 \\
\hline
\end{tabular}

$a-$ All MIC assays were performed in triplicate.

$b$ - flacp::BB0028 and flacp::BamA are compared with strain B31-A3-LK; BamD:: strep $^{R}$ is compared with strain B31-5A4NP1.

$c$ - flacp::BB0028 was grown in media without added IPTG.

$d$ - flacp::BamA was grown in media containing 0.05 mM IPTG.

appear to be significantly altered in either mutant since $\mathrm{BesC}$ levels in the protoplasmic cylinder (PC) fractions were comparable between BB0028 and BamD/BB0324 mutants and their respective parental strains (Figure 6A and B; BesC PC panels). As shown in Figure 6A (BamD panels) and Figure 6B (BB0028 panels), BB0028 and BamD/BB0324 expression levels and OM localization were not affected by the absence of BamD/BB0324 or BB0028, respectively. Membranes were also immunoblotted with antisera to CspA, an OM-localized lipoprotein, to ensure equivalent amounts of $\mathrm{PC}$ and $\mathrm{OM}$ fractions were loaded for the immunoblot analyses (Figure 6A and B; CspA panels). Finally, OppAIV, a known inner membrane lipoprotein, was used to confirm that the OM fractions were highly purified and devoid of contaminating PC components (Figure 6A and B; OppAIV panels). The combined analyses indicate that BesC export into the $\mathrm{OM}$ of $B$. burgdorferi is diminished in the BB0028 mutant but not in the BamD/BB0324 mutant.

\section{BamA independently interacts with BB0028 and BamD/ BB0324}

We have previously shown that BamA co-immunoprecipitates BamD/BB0324 and BB0028 [67]. These prior studies, however, did not examine whether BamD/BB0324 and BB0028 interact independently with BamA or if they actually interact with each other as a module and only BB0028 or BamD/BB0324 interacts in a specific manner with BamA. Therefore, as shown in Figure 7A, we performed co-immunoprecipitation assays using BamA (left panel) and BB0028 (right panel) specific antibodies in the BamD/ BB0324 mutant and wildtype strains. BamA and BB0028 could co-immunoprecipitate each other in the absence of BamD/BB0324. Similarly, as shown in Figure 7B, coimmunoprecipitations with BamA (left panel) and BamD/ BB0324 (right panel) specific antibodies revealed that BamA and BamD/BB0324 could co-immunoprecipitate each other in the absence of BB0028. The collective co-immunoprecipitation data indicate that BB0028 and BamD/BB0324 each independently interact with BamA.

\section{Discussion}

\section{The BAM complex in B. burgdorferi}

Currently, the predicted composition of the B. burgdorferi $\beta$-barrel assembly machine (BAM) complex consists of only three proteins: BamA, BB0028, and BamD/BB0324. The combined structural and functional data presented here are consistent with BB0028 and BB0324 being BamB and BamD orthologs, respectively. While we previously suggested that BB0324 is a BamD ortholog [67], the current data fully support the new designation of BamB for BB0028. Hereafter, we will refer to BB0028 as BamB and BB0324 as BamD. Further, the co-immunoprecipitation data revealed that the borrelial BamB and BamD lipoproteins interact specifically and independently with the central BamA protein, which is also entirely consistent
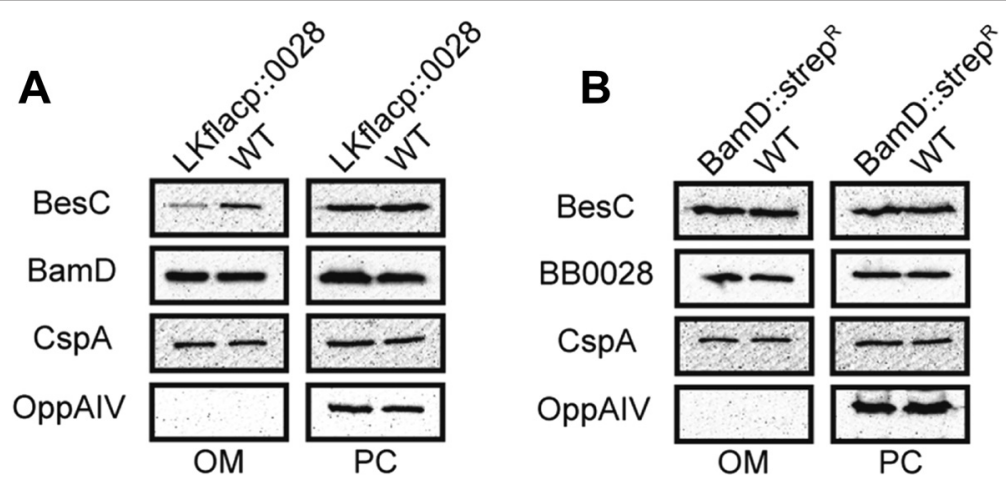

Figure 6 Absence of BB0028 results in decreased BesC in the B. burgdorferi OM. A. Outer membrane (OM) and protoplasmic cylinder (PC) fractions were isolated from the BB0028 mutant (LKflacp::0028) and parental (WT) strains for immunoblot analysis using antibodies specific for BesC, BamD/BB0324, CspA, and OppAIV. B. OM and PC fractions were isolated from the BamD/BB0324 mutant (BamD::strep ${ }^{\mathrm{R}}$ ) and its parental wildtype (WT) strain and immunoblotted with antibodies specific for BesC, BB0028, CspA, and OppAIV. 


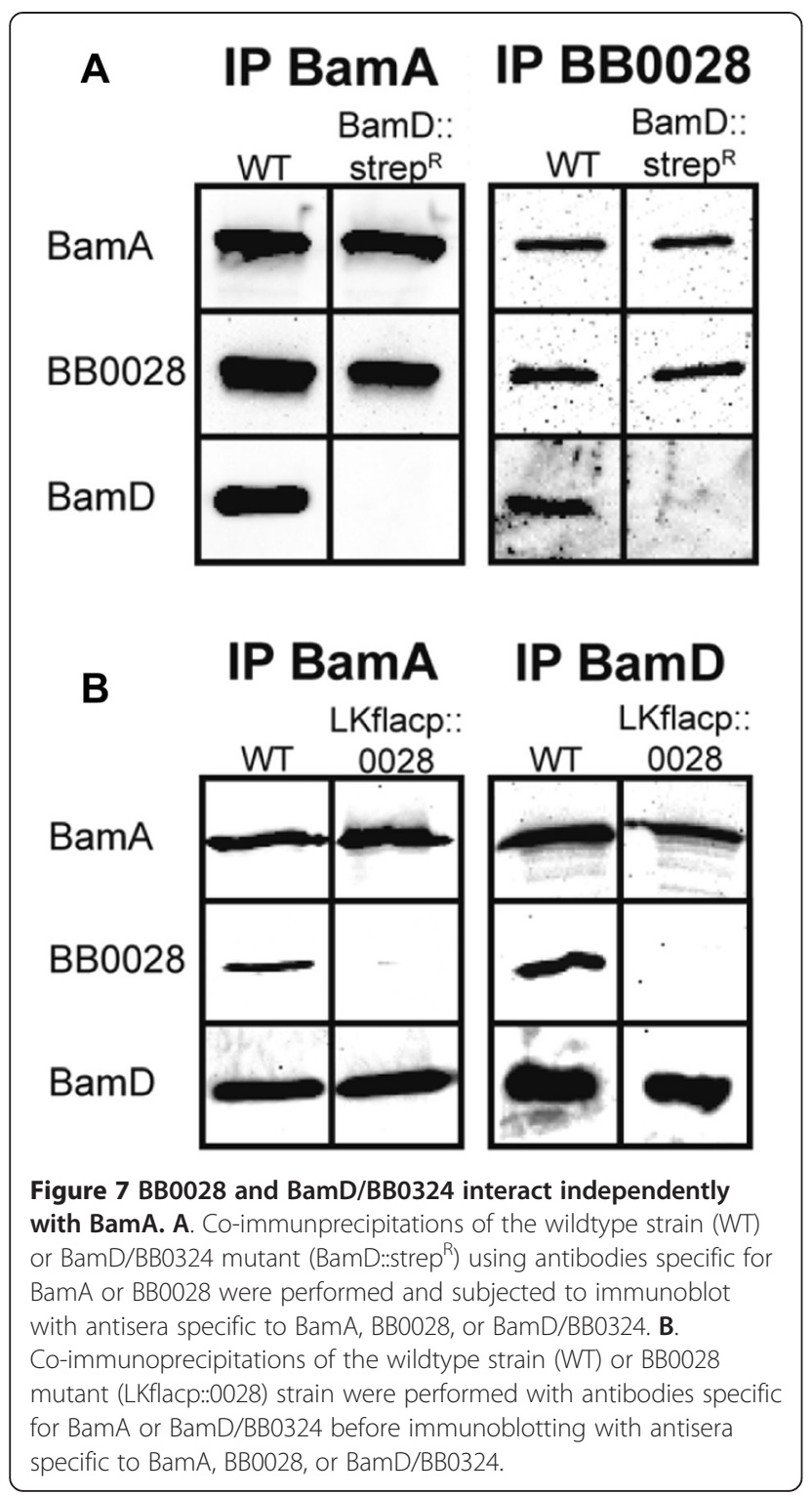

with this newly proposed nomenclature. The combined data provided in this report have led us to also propose a new working model for the B. burgdorferi BAM complex where BamD and BamB each interact directly and independently with the BamA protein (Figure 8). Future studies will be needed to fully dissect the specific interactions between BamB and BamD with the periplasmic polypeptide transport-associated (POTRA) domains of BamA in B. burgdorferi.

Structural models for the B. burgdorferi BamA, BamB, and BamD proteins

The recent crystal structures of BamA from $N$. gonorrhoeae, $H$. ducreyi, and E. coli $[35,36]$ allowed us to refine the prior model of the borrelial BamA protein [25].
While all three of these structures are highly conserved, there is only between $49-62 \%$ similarity between the $N$. gonorrhoeae, H. ducreyi, and E. coli BamA proteins. This indicates that while the BamA proteins from different organisms are highly conserved at the three-dimensional level, they are quite divergent at the primary sequence level. For example, the $N$. gonorrhoeae BamA protein shares between 29-52\% sequence similarity to BamA orthologs from other bacterial phyla. Accordingly, B. burgdorferi BamA is 33\% similar to N. gonorrhoeae BamA but was predicted to be highly conserved structurally. The model predicted for B. burgdorferi BamA contains a Cterminal $\beta$-barrel region consisting of 16 transmembrane domains and five POTRA domains along with a unique $\alpha$-helical region within extracellular loop four, which is a conserved feature that has been identified in all BamA crystal structures reported to date $[35,36]$. Extracellular loop six in B. burgdorferi was predicted to be elongated and associated with the lumen of the protein, which is also similar to the known BamA structures [35,36]. Additionally, as recently highlighted by Albrecht and co-workers [35], extracellular loop six of all known BamA structures contains a conserved three amino acid arginine-glycine-phenylalanine/tyrosine triad, referred to as the RGF motif, which has been shown to be essential for BamA function [43,71-73]. Interestingly, extracellular loop six in the predicted B. burgdorferi BamA structure was observed to contain an RGW triad, which is consistent with it corresponding to the RGF motif given that the $R$ and $G$ are identical and the third amino acid is aromatic (W) like in all other RGF motifs identified to date [72]. Future site-directed mutational studies will be required to determine if this RGW triad plays an important role in B. burgdorferi BAM function.

Structural modeling of the borrelial accessory lipoproteins revealed that the $\mathrm{BamB}$ protein folds into a $\beta$ propeller, which is a structure conserved among all BamB orthologs $[54,77,80]$. This structural conservation, combined with its specific interaction with BamA, is consistent with the conclusion that BB0028 is the borrelial BamB ortholog. The B. burgdorferi BamD protein was predicted to form a helix-loop-helix structure consisting of five $\alpha$-helices stacked on top of each other. This same type of folding and helix stacking is also found in the solved structures of the BamD orthologs from $E$. coli and Rhodothermus marinus [49,75,76]. Interestingly, the BamD ortholog in B. burgdorferi is C-terminally truncated and is half the size, or less, compared with other BamD orthologs [51,75]. The C-terminal portion of BamD has previously been reported to be integral to mediating the interaction between BamD and BamC in E. coli [81]. The apparent lack of a BamC ortholog in B. burgdorferi would be consistent with the $\mathrm{C}$-terminal region of BamD being dispensable in B. burgdorferi. This finding also further 


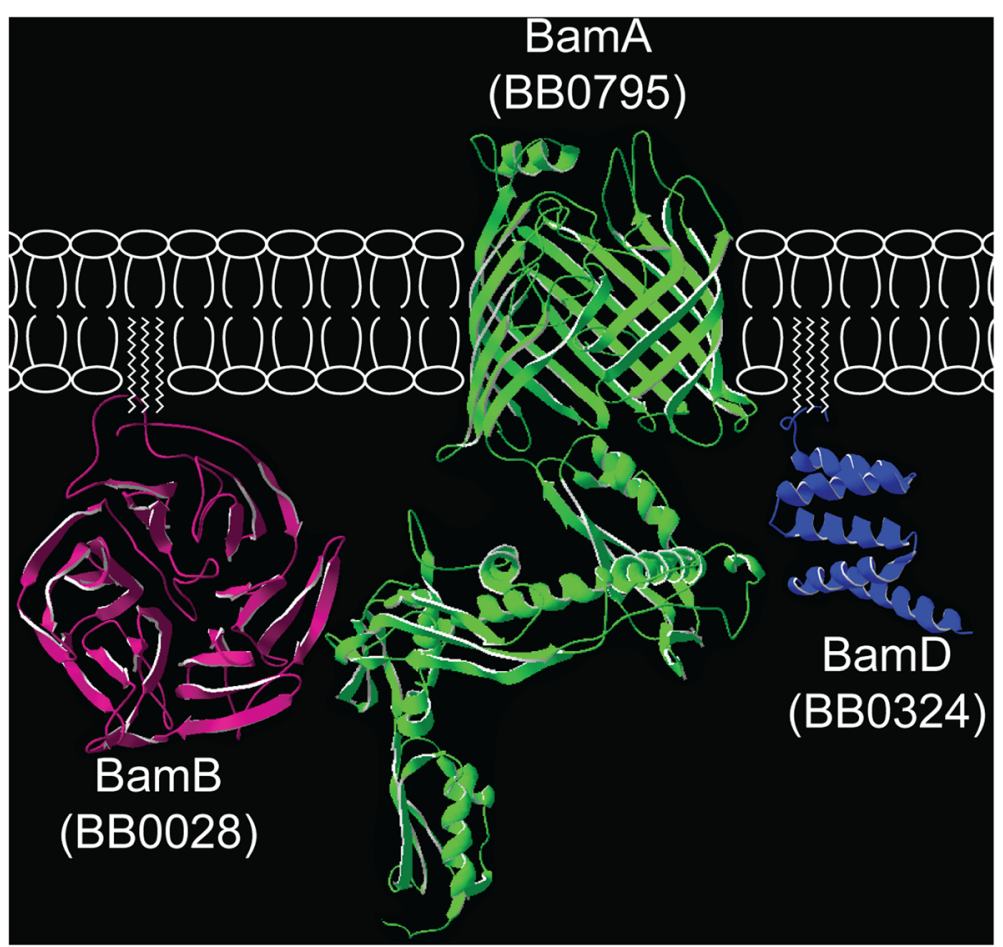

Figure 8 Current structural model of the tripartite $B$. burgdorferi BAM complex. The BAM complex in B. burgdorferi deduced from the combined structural models and co-immunoprecipitation data. The accessory lipoproteins BamD (BB0324, blue) and BamB (BB0028, purple) interact independently with the periplasmic POTRA domains of BamA (BB0795, green).

supports the notion that the BAM complex in B. burgdorferi is limited to BamA, BamB, and BamD.

\section{Functional roles of BamB and BamD in B. burgdorferi}

While we were able to generate a $\operatorname{bamD}$ null mutant, we were initially unable to generate a $\operatorname{bam} B$ knockout. To overcome this obstacle, we utilized an IPTG-regulatable promoter system to control expression of BamB so we could examine the role of BamB in the borrelial BAM complex. Interestingly, the BamB regulatable mutant grew in the absence of IPTG and was shown to lack BamB protein expression. This finding suggests BamB is not essential, at least for in vitro growth, in B. burgdorferi. Lack of BamB expression, however, did impact the overall physiology of the organism as the BamB mutant had a doubling time $75 \%$ greater than that of the parental strain. While the BamB null mutant had a marked growth phenotype, which is similar to what has been observed in an E. coli BamB mutant [79], it was surprising that the borrelial BamD mutant had no observable growth defect given that BamD orthologs have been reported to be essential in all bacteria studied to date $[51,78,81]$ other than Salmonella enteritidis [66]. In the case of $S$. enteritidis, however, while BamD is not essential, the null mutant has a substantially compromised growth rate and reduced viability as compared to the parental strain [66]. Additionally, S. enteritidis BamD mutants show reduced amounts of export of OmpA into their OMs [66]. Given that B. burgdorferi has at least 10 -fold fewer OMPs relative to surface area than the typical Gram-negative organism, this may suggest that the role of $\mathrm{BamD}$ is unique in this spirochete [24]. Future studies examining OMP export in the BamD mutant will be required to better understand the role of BamD in the borrelial BAM complex, OMP export, and OM permeability/integrity.

BAM accessory protein mutants have been shown to have altered membrane integrity and/or impaired export of OMPs in other organisms studied [51,64,78,79]. Consistent with this latter observation, we also observed a distinct decrease in the amount of BesC exported into the OM of the BamB mutant, which could explain the differing antibiotic susceptibility profiles observed between the BamB and BamD mutants. The antibiotics we utilized for susceptibility testing typically enter the bacterial cell either through aqueous channels such as porins (i.e., carbenicillin, cefotaxime, and tetracycline) or by traversing the lipid bilayer (i.e., minocycline) $[82,83]$. Given that BesC can form channels in lipid bilayers [27], it is tempting to speculate that the reduction in the $\mathrm{OM}$ of BesC in the BamB mutant correlates with increased susceptibility to the pore-transiting antibiotics carbenicillin 
and tetracycline. By contrast, the BamD mutant was eightfold more susceptible to the membrane permeable antibiotic minocycline as compared to the BamB mutant, suggesting that membrane integrity is altered in the BamD mutant, which could lead to enhanced diffusion of this hydrophobic antibiotic across the OM. While future studies will be required to better examine global effects of BamB and BamD on OMP export and membrane integrity, the antibiotic susceptibility and OMP trafficking data presented here provide evidence that both of these BAM accessory proteins play important, although different, roles in B. burgdorferi physiology and OM biogenesis.

\section{Conclusions}

In summary, we have shown that B. burgdorferi BamA, $B a m B$, and $B a m D$ are predicted to be structurally very similar to other known BamA, BamB, and BamD orthologs. Through generation and characterization of $\mathrm{BamB}$ and BamD mutants in B. burgdorferi, we have shown that BamB has a major effect on physiology and growth rate and both BamB and BamD mutants exhibit altered sensitivity profiles to various antimicrobial compounds. The combined results suggest that they play distinct roles in OMP trafficking and membrane composition. Additionally, the absence of BamB results in a decrease in the presence of the OMP BesC in the borrelial OM, which may account for its altered sensitivity profile to various antibiotics, especially the more hydrophilic antimicrobials such as carbenicillin and tetracycline. BamB and BamD were observed to interact specifically and independently with BamA, which led to our newly proposed working model of the tripartite B. burgdorferi BAM complex. The BAM complex model provided here lays the foundation for future studies aimed at dissecting the interaction among the BAM complex components, which should better elucidate $\mathrm{OM}$ biogenesis in this unique spirochete.

\section{Methods}

\section{Bacterial strains and growth conditions}

B. burgdorferi strains B31cF [84], B31cF BamA::cMyc, B31-A3-LK [85], B31-5A4NP1 [86], BamD::strep ${ }^{\text {, }}$, LKflacp::BamA [25], and LKflacp::0028 were cultivated at $34^{\circ} \mathrm{C}$ in BSK-II medium containing $6 \%$ heat-inactivated rabbit serum (complete BSK-II), supplemented when appropriate with $200 \mu \mathrm{g} / \mathrm{ml}$ kanamycin, $100 \mu \mathrm{g} / \mathrm{ml}$ streptomycin, $40 \mu \mathrm{g} / \mathrm{ml}$ gentamicin, and/or $1 \mathrm{mM}$ or $0.05 \mathrm{mM}$ IPTG. The cloning vector pBluescript-II KS+ (Stratagene, La Jolla, CA) and shuttle vector pBSV2 [87] were propagated using E. coli strains DH5 $\alpha$ or XL1-Blue (Stratagene) grown in lysogeny broth (LB) or LB agar supplemented with appropriate antibiotics.

\section{Structural modeling}

BamA was modeled by the I-TASSER protein structure and function prediction algorithm [68-70] using the solved crystal structure of $N$. gonorrhoeae BamA [36] as a template. BB0028 and BamD/BB0324 were modeled by the I-TASSER algorithm without selection of a crystal structure template. The resulting structural predictions in .pdb format, as well as the crystal structure .pdb files for N. gonorrhoeae BamA [PDB:4K3B], E. coli BamB [PDB:2YH3], and E. coli BamD [PDB:2YHC], were visualized using Swiss-PdbViewer molecular visualization software [88].

\section{Generation of antibodies}

The DNA sequence encoding BamA POTRA domains P1-P4, plus 14 amino acids of P5, was amplified from $B$. burgdorferi B31 genomic DNA using primers BamA P1 (NheI) F and BamA P4 + 14 (XhoI) R (Primers shown in Table 2). The DNA sequence encoding mature BB0028, lacking the N-terminal leader peptide, was amplified from $B$. burgdorferi B31 genomic DNA using primers $b b 0028$ (NheI) F and bb0028 (XhoI) R. The bamA P1-4 + 14 and $b b 0028$ amplicons were then cloned into NheI and XhoI restriction sites of the the pET23a cloning vector (EMD Millipore, Darmstadt, Germany), and the resulting constructs were electroporated into E. coli Overexpress ${ }^{\mathrm{m}}$ C41(DE3) (Lucigen Corp, Middleton, WI). His-tagged BamA P1-4+14 and BB0028 proteins were then purified as previously described $[89,90]$. Antibodies were generated against the recombinant BamA $\mathrm{P} 1-4+14$ and BB0028 proteins by Harlan Bioproducts for Science, Inc. (Madison, WI). Rat antibodies recognizing BamD/ BB0324, BesC, CspA, OppAIV, and FlaB were described elsewhere [22,25,67].

\section{Generation of $B$. burgdorferi mutants}

The c-Myc tag was inserted into a predicted loop of the BamA protein as follows. The first 1,581 nucleotides of bamA (open reading frame bb0795) were amplified from B. burgdorferi B31 genomic DNA using the primers bb0795A (BamHI) F and bb0795A (XbaI) R and were subsequently inserted into the shuttle vector pBSV2 using the restriction sites BamHI and XbaI. The final 860 nucleotides of bamA were then PCR-amplified using the primers bb0795B (SalI) F and bb0795 (PstI) R and inserted into the SalI and PstI sites of the vector construct. The borrelial promoter $f \lg B$ was then PCR-amplified from pBSV2 using the primers flgB (BamHI) $\mathrm{F}$ and flgB (BamHI) R, and the amplicon was inserted into the vector using the restriction site BamHI. Two 48-mer oligonucleotides, c-Myc (XbaI-SalI) F and c-Myc (XbaI-SalI) RC, encoding the 30-nucleotide c-Myc tag as well as 5' $\mathrm{XbaI}$ and 3' Sall sites, were then annealed together, digested with XbaI and SalI, and inserted into the construct. Fifteen 
Table 2 Oligonucleotides used in this study

\begin{tabular}{|c|c|c|}
\hline Name & Sequence $\left(5^{\prime}\right.$ to $3^{\prime}$, restriction sites in bold) & Description \\
\hline BamA P1 (Nhel) F & GCGGCTAGCAAGGGGAAAATAATAAAGGGTAT & $\begin{array}{l}\text { bamA nucleotides } 82-104 \text { plus Nhel site } \\
\text { (N-terminus of POTRA 1) }\end{array}$ \\
\hline BamA P4 + 14 (Xhol) R & GCGCTCGAGATTITATTTTAGAAACAGTAATAG & $\begin{array}{l}\text { Complementary to bamA nucleotides 1079-1104 } \\
\text { plus Xhol site (14 aa into POTRA } 5 \text { domain) }\end{array}$ \\
\hline bb0028 (Nhel) F & GCGGCTAGCCTGCAAAAAATAAAACATGAATAC & b60028 nucleotides 109-132 plus Nhel site \\
\hline bb0028 (Xhol) R & GCGCTCGAGTTCTTAGTTAATTTCTGTTTCC & $\begin{array}{l}\text { Complementary to b60028 nucleotides 1023-1047 } \\
\text { plus Xhol site }\end{array}$ \\
\hline 795a (BamHI) F & GCGGGATCCATGGGTTCAATTAGAGGTTTGT & bamA nucleotides 1-22 plus BamHI site \\
\hline 795a (Xbal) R & GCGTCTAGAATCAGGAACTTCCCTCTTGC & $\begin{array}{l}\text { Complementary to bamA nucleotides 1562-1581 } \\
\text { plus Xbal site }\end{array}$ \\
\hline 795b (Sall) F & GCGGTCGACCCATTTACAAGTTGGGAAGAAT & bamA nucleotides 1582-1593 plus Sall site \\
\hline $795 b($ Pstl) R & GCGCTGCAGTCAATATCTCATCTCAATTCCTA & $\begin{array}{l}\text { Complementary to bamA nucleotides 1562-1581 } \\
\text { plus Xbal site }\end{array}$ \\
\hline flgB $(\mathrm{BamHI}) \mathrm{F}$ & GCGGGATCCTACCCGAGCTTCAAGGAAGAT & flgB promoter nucleotides 1-21 plus BamHI site \\
\hline flgB (BamHI) R & GCGGGATCCATGGAAACCTCCCTCATTTAAA & $\begin{array}{l}\text { Complementary to flgB nucleotides } 387-408 \text { plus } \\
\text { BamHI site }\end{array}$ \\
\hline c-Myc (Xbal-Sall) F & GCGTCTAGAGAACAAAAACTTATTTCTGAAGAAGATCTGGTCGACGCG & c-Myc tag plus $5^{\prime}$ Xbal and $3^{\prime}$ Sall sites \\
\hline c-Myc (Xbal-Sall) RC & GCGGTCGACCAGATCTTCTTCAGAAATAAGTTTTTGTTCTCTAGACGC & $\begin{array}{l}\text { Complementary to c-Myc tag plus 5' Sall and } \\
\text { 3' Xbal sites }\end{array}$ \\
\hline KO324 downstream (Kpnl) F & GCGGGTACCGATTATTTGGGCAGATATCAAG & $\begin{array}{l}\text { Complementary to nucleotides 330,248-330,269 } \\
\text { of B31 chromosome ( } 600 \text { bp downstream of } \\
\text { b60324) plus Kpnl site }\end{array}$ \\
\hline KO324 downstream (Xhol) R & GCGCTCGAGTAATTTAAGAAATAAAAATTITTACTG & $\begin{array}{l}\text { Nucleotides 329,622-329,648 of B31 chromosome } \\
\text { (immediately downstream of b60324) plus Xhol site }\end{array}$ \\
\hline KO324 upstream (BamHI) F & GCGGGATCCTTATAGCAATAATAAGCTTATAAAG & $\begin{array}{l}\text { Nucleotides } 328,661-328,685 \text { of B31 chromosome } \\
\text { (600 bp upstream of bb0324) plus BamHI site }\end{array}$ \\
\hline KO324 upstream (EcoRI) R & GCGGAATTCTTCTGCCTCTITAAGAATGTTT & $\begin{array}{l}\text { Complementary to nucleotides } 329,239-329,262 \text { of } \\
\text { B31 chromosome (immediately upstream of } \\
\text { b60324), plus EcoRl site }\end{array}$ \\
\hline $\mathrm{flgB}(\mathrm{Xhol}) \mathrm{F}$ & GCGCTCGAGTACCCGAGCTTCAAGGAAG & flgB nucleotides 1-21 plus Xhol site \\
\hline Strep (EcoRI) R & GCGGAATTCTTATTTGCCGACTACCTTGGTGAT & $\begin{array}{l}\text { Complementary to aadA nucleotides } 769-792 \text { plus } \\
\text { EcoRl site }\end{array}$ \\
\hline 0028 F 4-29 (EcoRI\&Ndel) & GCGGAATTCCATATGAAACAAAAATACGAAAACTATTTAA & bb0028 nucleotides 4-29 plus EcoRl and Ndel sites \\
\hline 0028 R 678-699 (BamHI) & GCGGGATCCACCACCAGTCATTACTAAAACT & $\begin{array}{l}\text { Complementary to bb0028 nucleotides 678-699 } \\
\text { plus BamHI site }\end{array}$ \\
\hline 0027 F 4-29 (Kpnl) & GCGGGTACCAGAAAGTATATTTTTATAATACTAAT & bb0027 nucleotides 4-29 plus Kpnl site \\
\hline 0027 R 613-636 (Xhol) & GCGCTCGAGCAATTATTTACATTCACTGTAAC & $\begin{array}{l}\text { Complementary to bb0027 nucleotides 613-636 } \\
\text { plus Xhol site }\end{array}$ \\
\hline
\end{tabular}

to $20 \mu \mathrm{g}$ of the final construct was then electroporated into B. burgdorferi strain B31-cF and selected for on the basis of kanamycin resistance to yield strain B31-cF BamA::c-Myc.

The bamD/bb0324 gene was deleted in B. burgdorferi strain B31-5A4NP1 by the following method. First, the 600 -nucleotide region immediately upstream of bamD/ bb0324 was amplified from B. burgdorferi B31 genomic DNA using the primers KO324 upstream (BamHI) F and KO324 upstream (EcoRI) R, and cloned into the pBluescript II KS+ cloning vector. The 600-nucleotide region immediately downstream of $\mathrm{bamD/bb0324}$ was then amplified with primers KO324 downstream (KpnI)
$\mathrm{F}$ and $\mathrm{KO} 324$ downstream (XhoI) $\mathrm{R}$ and inserted into the KpnI and XhoI sites of the vector. A cassette containing the $f \lg B$ promoter and $\operatorname{aad} A$ streptomycin resistance gene was then amplified from the pKFSS1 [91] plasmid using the primers flgB (XhoI) F and Strep (EcoRI) R, and the amplicon was inserted into the vector using XhoI and EcoRI. The final construct was then electroporated into B. burgdorferi strain B31-5A4NP1 and selected with $100 \mu \mathrm{g} / \mathrm{ml}$ streptomycin to yield strain BamD::strep ${ }^{\mathrm{R}}$. Potential positive clones were screened by PCR using the primers KO324 upstream (BamHI) F and KO324 downstream (KpnI) F, and immunoblotted with anti-BamD/BB0324 antibodies to verify the absence of 
BamD/BB0324 in whole cell lysates. The final BamD:: strep $^{\mathrm{R}}$ isolate was subjected to complete plasmid analysis and was found to possess all plasmids except cp9, which was previously shown to be absent from the parental B31-5A4NP1 strain [86].

To generate a regulatable BB0028 mutant, the hybrid flacp promoter [85] was inserted upstream of the $b b 0028$ gene. Nucleotides 4-699 of $b b 0028$ were amplified from $B$. burgdorferi $\mathrm{B} 31$ genomic DNA using the primers $0028 \mathrm{~F}$ 4-29 (EcoRI\&NdeI) and 0028 R 678-699 (BamHI) and cloned into the multiple cloning site of the pBluescript II $\mathrm{SK}+$ cloning vector using the restriction sites EcoRI and BamHI. A cassette containing the constitutive $f l g B$ promoter, the aadA streptomycin-resistance gene, and the hybrid flacp promoter was then digested from the pTLflacp::795 construct [25] previously generated in our laboratory and cloned into the XhoI and NdeI sites of the vector. Finally, nucleotides 4-636 of bb0027 were amplified using primers $0027 \mathrm{~F} 4-29$ (KpnI) and $0027 \mathrm{R}$ 613-636 (XhoI), and the resulting amplicon was then inserted upstream of the streptomycin-resistance cassette using the restriction enzymes KpnI and XhoI. The final construct was subsequently electroporated into $B$. burgdorferi strain B31-A3-LK and grown in the presence of $1 \mathrm{mM}$ IPTG and selected with streptomycin to yield strain LKflacp::0028. Potential positive clones were screened by PCR using the primers 0027 F 4-29 (KpnI) and 0028 R 678-699 (BamHI). To verify IPTG-regulation of BB0028 from the flacp promoter, whole-cell lysates were immunoblotted with anti-BB0028 antibodies. The final LKflacp::0028 isolate was subjected to a complete plasmid analysis and was found to possess all plasmids except cp9, which was previously shown to be absent from the parental B31-A3-LK strain $[85,92,93]$.

\section{Surface localization assay}

B. burgdorferi strain B31-cF BamA::c-Myc and wildtype B31-cF organisms were enumerated and diluted to a concentration of $5 \times 10^{6}$ cells per $\mathrm{ml}$ in complete BSK-II medium. For surface localization assays, wildtype B31-cF and BamA::c-Myc-expressing cell suspensions were then co-incubated with rabbit anti-c-Myc antibody (SigmaAldrich, St. Louis, MO, dilution of 1:20) and rat antiFlaB (dilution of 1:500) for one hour. The cells were gently pelleted at $4000 \times g$ and washed three times with PBS. The final pellet was resuspended in $100 \mu \mathrm{l}$ PBS, and $10 \mu \mathrm{l}$ aliquots were spotted on glass slides and allowed to air dry overnight. Slides were subsequently fixed for 10 minutes with acetone and then blocked for 30 minutes in PBS containing 0.5\% BSA. Samples were incubated for 45 minutes with Alexa-Fluor 488-conjugated goat anti-rabbit antibodies (1:250 dilution; Life Technologies, Grand Island, NY) and Alexa-Fluor 568-conjugated goat anti-rat antibodies (1:500 dilution; Life Technologies).
After incubation, all samples were washed three times in blocking buffer and mounted in buffered glycerol containing 4;6-diamidino-2-phenylindole dihydrochloride (DAPI; Vector Laboratories, Burlingame, CA). As a control, samples were also washed, spotted onto glass slides, and fixed with acetone prior to incubation with rabbit anti-c-Myc antibody and rat anti-FlaB for one hour. Slides were visualized at 1000X magnification on an Olympus BX60 fluorescent microscope (Olympus America Inc, Center Valley, PA).

\section{Immunoblotting}

After blocking in milk buffer composed of phosphate buffered saline, $5 \%$ nonfat dried milk, and $0.5 \%$ Tween, polyvinylidine fluoride membranes were incubated for one hour with rat antisera at the following dilutions in milk buffer: 1:2000 for anti-BamA, anti-BB0028, anti-OppAIV, and anti-BesC; 1:1000 for anti-BamD and anti-CspA. Membranes were then washed three times, incubated in milk buffer with a 1:10,000 dilution of HRPconjugated goat anti-rat antibodies (Bio-Rad, Hercules, $\mathrm{CA}$ ), and washed three additional times. Immunoblots were developed by enhanced chemiluminescence (Amersham Biosciences, Piscataway, NJ).

\section{Growth assays}

Triplicate $14 \mathrm{ml}$ cultures were seeded at 3000 Borrelia/ $\mathrm{ml}$ and grown at $34^{\circ} \mathrm{C}$ in complete BSK-II containing appropriate antibiotics and IPTG as necessary. Cultures were then enumerated at 24-hour intervals by dark field microscopy until reaching stationary phase, and the mean Borrelia $/ \mathrm{ml}$ were plotted for each strain at each time point. To ensure appropriate IPTG regulation of BB0028 at all phases of growth, samples of the LK and LKflacp::0028 strains were taken at mid-log (approx. $1 \times$ $10^{7}$ Borrelia/ml; day 4 for LK, day 6 for LKflacp::0028) and stationary (day 6 for LK, day 10 for LKflacp::0028) phases, and whole-cell lysates were prepared and immunoblotted with rat BB0028 antibodies. Standard deviation for each timepoint was determined and is shown by error bars in Figure 5 .

\section{Antimicrobial susceptibility assays}

Antimicrobial susceptibility was determined by a method adapted from Bunikis, et al. and Hunfeld, et al. [27,94]. Antimicrobial agents were serially diluted in a 96-well microtiter plate in a volume of $100 \mu \mathrm{l}$ complete BSK-II per well. Each well was then inoculated with $100 \mu \mathrm{l}$ of complete BSK-II media containing strain-specific antibiotics and IPTG, if necessary, and $5 \times 10^{7}$ Borrelia $/ \mathrm{ml}$, for a final cell density of $2.5 \times 10^{7}$ Borrelia $/ \mathrm{ml}$. The concentration ranges for each antimicrobial agent tested were as follows $(\mathrm{ng} / \mathrm{ml})$ : carbenicillin 2-5000; cefotaxime 5-10,000; tetracycline 5-10,000; and minocycline 5-10,000. 
Plates were then sealed with laboratory film and incubated for 72 hours at $34^{\circ} \mathrm{C}$ with $5 \% \mathrm{CO}_{2}$. At 0-, 24-, 48-, and $72-$ hour timepoints, the absorbance of each well was measured at $562 \mathrm{~nm}$ and $630 \mathrm{~nm}$ using a Molecular Devices SpectraMax 340 plate reader (Molecular Devices, Sunnyvale, $\mathrm{CA}$ ). Each assay was repeated in triplicate, and the mean 562/630 nm ratio, corresponding to the amount of growth in each well, for each concentration of each antimicrobial agent was then plotted with respect to time to determine the minimum inhibitory concentration of each antibiotic.

\section{Isolation of $B$. burgdorferi $\mathrm{OM}$ vesicles}

B. burgdorferi outer membrane $(\mathrm{OM})$ and protoplasmic cylinder (PC) fractions were isolated as previously described $[25,95,96]$. Equivalent amounts of $\mathrm{OM}$ and $\mathrm{PC}$ fractions were then separated by SDS-PAGE and immunoblotted with appropriate antibodies. To ensure equivalent loading of $\mathrm{OM}$ and $\mathrm{PC}$ fractions, membranes were immunoblotted for the OM lipoprotein CspA [22,97]. To ensure proper fractionation of $\mathrm{OM}$ and $\mathrm{PC}$ fractions, membranes were also immunoblotted for the lipoprotein OppAIV, which is known to localize to the inner membrane $[96,98]$.

\section{Co-immunoprecipitation}

Lysates of B. burgdorferi strains B31-5A4NP1, BamD:: strep $^{\mathrm{R}}$, B31-A3-LK, and LKflacp::0028 were prepared for co-immunoprecipitation studies as previously described [67]. Co-immunoprecipitation was performed according to manufacturer's protocol using the Pierce Crosslink Immunoprecipitation Kit (Pierce Biotechnologies, Rockford, IL). Briefly, $250 \mu \mathrm{l}$ lysate from each strain was precleared and then applied in IP/Lysis Buffer to Protein A/ G columns treated and crosslinked with $10 \mu \mathrm{l}$ of antiserum to BamA, BB0028, or BamD. After incubation at $4^{\circ} \mathrm{C}$ for 3 hours, columns were washed and the bound protein was eluted in low $\mathrm{pH}$ elution buffer for later analysis by SDS-PAGE and immunoblotting.

\section{Abbreviations \\ BAM: $\beta$-barrel assembly machine; OM: Outer membrane; OMP: Outer membrane protein; POTRA: Polypeptide transport-associated; \\ TPR: Tetratricopeptide repeat; PC: Protoplasmic cylinder.}

\section{Competing interests}

The authors declare that they have no competing interests.

\section{Authors' contributions}

JD carried out all experiments and drafted the initial manuscript. MK participated in the design of the studies and provided intellectual input and editing assistance for the manuscript. HI provided recombinant BamA protein for antibody production and helped edit the manuscript. DA conceived the study, oversaw its design and coordination, and helped to draft and edit the manuscript. All authors read and approved the final manuscript.

\section{Acknowledgements}

We would like to thank Dr. Scott Samuels for providing the flacp promoter and B. burgdorferi B31-A3-LK strain. We would also like to thank Cecilia Nguyen for expert technical assistance. This work was supported by grant Al059373 from NIH/NIAID to DRA.

Received: 14 January 2015 Accepted: 12 March 2015

Published online: 24 March 2015

\section{References}

1. Benach JL, Bosler EM, Hanrahan JP, Coleman JL, Habicht GS, Bast TF, et al. Spirochetes isolated from the blood of two patients with Lyme disease. N Engl J Med. 1983:308:740-2.

2. Steere AC, Grodzicki RL, Kornblatt AN, Craft JE, Barbour AG, Burgdorfer W, et al. The spirochetal etiology of Lyme disease. N Engl J Med. 1983;308:733-40.

3. van Dam AP, Kuiper H, Vos K, Widjojokusumo A, de Jongh BM, Spanjaard L, et al. Different genospecies of Borrelia burgdorferi are associated with distinct clinical manifestations of Lyme borreliosis. Clin Infect Dis. 1993;17:708-17.

4. Takayama K, Rothenberg RJ, Barbour AG. Absence of lipopolysaccharide in the Lyme disease spirochete, Borrelia burgdorferi. Infect Immun. 1987;55:2311-3.

5. Howe TR, Mayer LW, Barbour AG. A single recombinant plasmid expressing two major outer surface proteins of the Lyme disease spirochete. Science. 1985:227:645-6.

6. Brandt ME, Riley BS, Radolf JD, Norgard MV. Immunogenic integral membrane proteins of Borrelia burgdorferi are lipoproteins. Infect Immun. 1990;58:983-91.

7. Fuchs R, Jauris S, Lottspeich F, Preac-Mursic V, Wilske B, Soutschek E. Molecular analysis and expression of a Borrelia burgdorferi gene encoding a $22 \mathrm{kDa}$ protein (pC) in Escherichia coli. Mol Microbiol. 1992;6:503-9.

8. Norris SJ, Carter CJ, Howell JK, Barbour AG. Low-passage-associated proteins of Borrelia burgdorferi B31: characterization and molecular cloning of OspD, a surface-exposed, plasmid-encoded lipoprotein. Infect Immun. 1992;60:4662-72.

9. Lam TT, Nguyen TPK, Montgomery RR, Kantor FS, Fikrig E, Flavell RA. Outer surface proteins $\mathrm{E}$ and $\mathrm{F}$ of Borrelia burgdorferi, the agent of Lyme disease. Infect Immun. 1994;62:290-8.

10. Guo B, Norris SJ, Rosenberg LC, Hook M. Adherence of Borrelia burgdorferi to the proteoglycan decorin. Infect Immun. 1995;63:3467-72.

11. Fraser $C M$, Casjens S, Huang WM, Sutton GG, Clayton R, Lathigra $R$, et al. Genomic sequence of a Lyme disease spirochaete, Borrelia burgdorferi. Nature. 1997;390:580-6.

12. Zhang JR, Hardham JM, Barbour AG, Norris SJ. Antigenic variation in Lyme disease Borreliae by promiscuous recombination of Vmp-like sequence cassettes. Cell. 1997:89:275-85.

13. Probert WS, Johnson BJB. Identification of a $47 \mathrm{kDa}$ fibronectin-binding protein expressed by Borrelia burgdorferi isolate B31. Mol Microbiol. 1998;30:1003-15.

14. Casjens S, Palmer N, van Vugt R, Huang WM, Stevenson B, Rosa P, et al. $A$ bacterial genome in flux: the twelve linear and nine circular extrachromosomal DNAs in an infectious isolate of the Lyme disease spirochete Borrelia burgdorferi. Mol Microbiol. 2000;35:490-516.

15. Wallich R, Pattathu J, Kitiratschky V, Brenner C, Zipfel PF, Brade V, et al. Identification and functional characterization of complement regulatoracquiring surface protein 1 of the Lyme disease spirochetes Borrelia afzelii and Borrelia garinii. Infect Immun. 2005;73:2351-9.

16. Bergstrom S, Zuckert WR. Structure, function and biogenesis of the Borrelia cell envelope. In: Samuels DS, Radolf JD, editors. Borrelia: Molecular biology, host interaction and pathogenesis. Norfolk, UK: Caister Academic Press; 2010. p. 139-66.

17. Revel AT, Blevins JS, Almazan C, Neil L, Kocan KM, de la FJ, et al. bptA (bbe16) is essential for the persistence of the Lyme disease spirochete, Borrelia burgdorferi, in its natural tick vector. Proc Natl Acad Sci U S A. 2005;102:6972-7.

18. Kraiczy P, Hartmann K, Hellwage J, Skerka C, Kirschfink M, Brade V, et al. Immunological characterization of the complement regulator factor $\mathrm{H}$-binding CRASP and Erp proteins of Borrelia burgdorferi. Int J Med Microbiol. 2004;293 Suppl 37:152-7. 
19. Hellwage J, Meri T, Heikkila T, Alitalo A, Panelius J, Lahdenne P, et al. The complement regulator factor $\mathrm{H}$ binds to the surface protein OspE of Borrelia burgdorferi. J Biol Chem. 2001;276:8427-35.

20. Hartmann K, Corvey C, Skerka C, Kirschfink M, Karas M, Brade V, et al. Functional characterization of BbCRASP-2, a distinct outer membrane protein of Borrelia burgdorferi that binds host complement regulators factor $\mathrm{H}$ and FHL-1. Mol Microbiol. 2006;61:1220-36.

21. Hughes JL, Nolder CL, Nowalk AJ, Clifton DR, Howison RR, Schmit VL, et al. Borrelia burgdorferi surface-localized proteins expressed during persistent murine infection are conserved among diverse Borrelia spp. Infect Immun. 2008;76:2498-511.

22. Brooks CS, Vuppala SR, Jett AM, Akins DR. Identification of Borrelia burgdorferi outer surface proteins. Infect Immun. 2006;74:296-304.

23. Kenedy MR, Lenhart TR, Akins DR. The role of Borrelia burgdorferi outer surface proteins. FEMS Immunol Med Microbiol. 2012;66:1-19.

24. Radolf JD, Bourell KW, Akins DR, Brusca JS, Norgard MV. Analysis of Borrelia burgdorferi membrane architecture by freeze-fracture electron microscopy. J Bacteriol. 1994;176:21-31.

25. Lenhart TR, Akins DR. Borrelia burgdorferi locus BB0795 encodes a BamA orthologue required for growth and efficient localization of outer membrane proteins. Mol Microbiol. 2010;75:692-795.

26. Antonara S, Chafel RM, LaFrance M, Coburn J. Borrelia burgdorferi adhesins identified using in vivo phage display. Mol Microbiol. 2007:66:262-76.

27. Bunikis I, Denker K, Ostberg Y, Andersen C, Benz R, Bergstrom S. An RND-type efflux system in Borrelia burgdorferi is involved in virulence and resistance to antimicrobial compounds. PLoS Pathog. 2008;4:e1000009.

28. Coburn J, Cugini C. Targeted mutation of the outer membrane protein P66 disrupts attachment of the Lyme disease agent, Borrelia burgdorferi, to integrin alphavbeta3. Proc Natl Acad Sci U S A. 2003;100:7301-6.

29. Cugini C, Medrano M, Schwan TG, Coburn J. Regulation of expression of the Borrelia burgdorferi beta(3)-chain integrin ligand, P66, in ticks and in culture. Infect Immun. 2003;71:1001-7.

30. Noppa L, Ostberg Y, Lavrinovicha M, Bergstrom S. P13, an integral membrane protein of Borrelia burgdorferi, is C-terminally processed and contains surface-exposed domains. Infect Immun. 2001;69:3323-34.

31. Skare JT, Mirzabekov TA, Shang ES, Blanco DR, Erdjument-bromage $H$, Bunikis J, et al. The Oms66 (p66) protein is a Borrelia burgdorferi porin. Infect Immun. 1997;65:3654-61.

32. Wood E, Tamborero S, Mingarro I, Esteve-Gassent MD. BB0172, a Borrelia burgdorferi outer membrane protein that binds integrin a3b1. J Bacteriol. 2013;195:3320-30

33. Russell TM, Johnson BJ. Lyme disease spirochaetes possess an aggrecanbinding protease with aggrecanase activity. Mol Microbiol. 2013;90:228-40.

34. Knowles TJ, Scott-Tucker A, Overduin M, Henderson IR. Membrane protein architects: the role of the BAM complex in outer membrane protein assembly. Nat Rev Microbiol. 2009;7:206-14.

35. Albrecht R, Schutz M, Oberhettinger P, Faulstich M, Bermejo I, Rudel T, et al. Structure of BamA, an essential factor in outer membrane protein biogenesis. Acta Crystallogr D Biol Crystallogr. 2014;70:1779-89.

36. Noinaj N, Kuszak AJ, Gumbart JC, Lukacik P, Chang H, Easley NC, et al. Structural insight into the biogenesis of beta-barrel membrane proteins. Nature. 2013;501:385-90.

37. Noinaj N, Kuszak AJ, Balusek C, Gumbart JC, Buchanan SK. Lateral opening and exit pore formation are required for BamA function. Structure. 2014;22:1055-62.

38. Misra R, Stikeleather R, Gabriele R. In vivo roles of BamA, BamB and BamD in the biogenesis of BamA, a core protein of the b-barrel assembly machine of Escherichia coli. J Mol Biol. 2014:427:1061-74.

39. Gessmann D, Chung YH, Danoff EJ, Plummer AM, Sandlin CW, Zaccai NR, et al. Outer membrane $\beta$-barrel protein folding is physically controlled by periplasmic lipid head groups and BamA. Proc Natl Acad Sci U S A. 2014;111:5878-83.

40. Volokhina EB, Grijpstra J, Beckers F, Lindh E, Robert V, Tommassen J, et al. Species-specificity of the BamA component of the bacterial outer membrane protein-assembly machinery. PLoS One. 2013;8:e85799.

41. Hagan $\mathrm{CL}$, Westwood DB, Kahne D. Bam lipoproteins assemble BamA in vitro. Biochem. 2013;52:6108-13.

42. Ricci DP, Hagan CL, Kahne D, Silhavy TJ. Activation of the Escherichia coli beta-barrel assembly machine (Bam) is required for essential components to interact properly with substrate. Proc Natl Acad Sci U S A. 2012;109:3487-91.
43. Rigel NW, Ricci DP, Silhavy TJ. Conformation-specific labeling of BamA and suppressor analysis suggest a cyclic mechanism for beta-barrel assembly in Escherichia coli. Proc Natl Acad Sci U S A. 2013;110:5151-6.

44. Kleinschmidt JH, den BT, Driessen AJ, Tamm LK. Outer membrane protein A of Escherichia coli inserts and folds into lipid bilayers by a concerted mechanism. Biochem. 1999;38:5006-16.

45. Huysmans GH, Radford SE, Brockwell DJ, Baldwin SA. The N-terminal helix is a post-assembly clamp in the bacterial outer membrane protein PagP. J Mol Biol. 2007;373:529-40.

46. Burgess NK, Dao TP, Stanley AM, Fleming KG. Beta-barrel proteins that reside in the Escherichia coli outer membrane in vivo demonstrate varied folding behavior in vitro. J Biol Chem. 2008;283:26748-58.

47. Stanley AM, Fleming KG. The process of folding proteins into membranes: challenges and progress. Arch Biochem Biophys. 2008;469:46-66.

48. Walther D, Rapaport D, Tommassen J. Biogenesis of beta-barrel membrane proteins in bacteria and eukaryotes: evolutionary conservation and divergence. Cell Mol Life Sci. 2009;66:2789-804.

49. Webb CT, Heinz E, Lithgow T. Evolution of the beta-barrel assembly machinery. Trends Microbiol. 2012;20:612-20.

50. Ricci DP, Silhavy TJ. The Bam machine: A molecular cooper. Biochim Biophys Acta. 1818;2012:1067-84

51. Wu T, Malinverni J, Ruiz N, Kim S, Silhavy TJ, Kahne D. Identification of a Multicomponent Complex Required for Outer Membrane Biogenesis in Escherichia coli. Cell. 2005;121:235-45.

52. Jansen KB, Baker SL, Sousa MC. Crystal Structure of BamB Bound to a Periplasmic Domain Fragment of BamA, the Central Component of the beta-Barrel Assembly Machine. J Biol Chem. 2014;290:2126-36.

53. Kim S, Malinverni JC, Sliz P, Silhavy TJ, Harrison SC, Kahne D. Structure and Function of an Essential Component of the Outer Membrane Protein Assembly Machine. Science. 2007;317:961-4.

54. Noinaj N, Fairman JW, Buchanan SK. The crystal structure of BamB suggests interactions with BamA and its role within the BAM complex. J Mol Biol. 2011;407:248-60

55. Heuck A, Schleiffer A, Clausen T. Augmenting beta-augmentation: structural basis of how BamB binds BamA and may support folding of outer membrane proteins. J Mol Biol. 2011;406:659-66.

56. Reumann S, Davila-Aponte J, Keegstra K. The evolutionary origin of the protein-translocating channel of chloroplastic envelope membranes: Identification of a cyanobacterial homolog. Proc Natl Acad Sci U S A. 1999:96:784-9.

57. Gentle I, Gabriel K, Beech P, Waller R, Lithgow T. The Omp85 family of proteins is essential for outer membrane biogenesis in mitochondria and bacteria. J Cell Biol. 2004;164:19-24.

58. Voulhoux R, Tommassen J. Omp85, an evolutionarily conserved bacterial protein involved in outer-membrane-protein assembly. Res Microbiol. 2004;155:129-35

59. Genevrois S, Steeghs L, Roholl P, Letesson JJ, van der Ley P. The Omp85 protein of Neisseria meningitidis is required for lipid export to the outer membrane. EMBO J. 2003:22:1780-9.

60. Voulhoux R, Bos MP, Geurtsen J, Mols M, Tommassen J. Role of a Highly Conserved Bacterial Protein in Outer Membrane Protein Assembly. Science. 2003;299:262-5.

61. Anwari K, Poggio S, Perry A, Gatsos X, Ramarathinam SH, Williamson NA et al. A modular BAM complex in the outer membrane of the alphaproteobacterium Caulobacter crescentus. PLoS One. 2010:5:e8619.

62. Gatsos X, Perry AJ, Anwari K, Dolezal P, Wolynec PP, Likic VA, et al. Protein secretion and outer membrane assembly in Alphaproteobacteria. FEMS Microbiol Rev. 2008:32:995-1009.

63. Volokhina EB, Beckers F, Tommassen J, Bos MP. The beta-barrel outer membrane protein assembly complex of Neisseria meningitidis. J Bacteriol. 2009;191:7074-85.

64. Sklar JG, Wu T, Gronenberg LS, Malinverni JC, Kahne D, Silhavy TJ. Lipoprotein SmpA is a component of the YaeT complex that assembles outer membrane proteins in Escherichia coli. Proc Natl Acad Sci. 2007;104:6400-5.

65. Selkrig J, Mosbahi K, Webb CT, Belousoff MJ, Perry AJ, Wells TJ, et al. Discovery of an archetypal protein transport system in bacterial outer membranes. Nat Struct Mol Biol. 2012;19:506-10. S1.

66. Fardini Y, Trotereau J, Bottreau E, Souchard C, Velge P, Virlogeux-Payant Investigation of the role of the BAM complex and SurA chaperone in outer-membrane protein biogenesis and type III secretion system expression in Salmonella. Microbiology. 2009;155:1613-22. 
67. Lenhart TR, Kenedy MR, Yang X, Pal U, Akins DR. BB0324 and BB0028 are constituents of the Borrelia burgdorferi beta-barrel assembly machine (BAM) complex. BMC Microbiol. 2012;12:60

68. Zhang Y. I-TASSER server for protein 3D structure prediction. BMC Bioinformatics. 2008;9:40.

69. Roy A, Yang J, Zhang Y. COFACTOR: an accurate comparative algorithm for structure-based protein function annotation. Nucleic Acids Res. 2012;40:W471-7.

70. Roy A, Kucukural A, Zhang Y. I-TASSER: a unified platform for automated protein structure and function prediction. Nat Protoc. 2010;5:725-38.

71. Clantin B, Delattre AS, Rucktooa P, Saint N, Meli AC, Locht C, et al. Structure of the Membrane Protein FhaC: A Member of the Omp85-TpsB Transporter Superfamily. Science. 2007;317:957-61.

72. Browning DF, Matthews SA, Rossiter AE, Sevastsyanovich YR, Jeeves M, Mason $J$, et al. Mutational and topological analysis of the Escherichia coli BamA protein. PLoS One. 2013;8:e84512.

73. Leonard-Rivera M, Misra R. Conserved residues of the putative L6 loop of Escherichia coli BamA play a critical role in the assembly of $\beta$-barrel outer membrane proteins, including that of BamA itself. J Bacteriol. 2012;194:4662-8.

74. Blatch GL, Lassle M. The tetratricopeptide repeat: a structural motif mediating protein-protein interactions. Bioessays. 1999;21:932-9.

75. Dong $C$, Hou HF, Yang X, Shen YQ, Dong YH. Structure of Escherichia coll BamD and its functional implications in outer membrane protein assembly. Acta Crystallogr D Biol Crystallogr. 2012;68:95-101.

76. Sandoval CM, Baker SL, Jansen K, Metzner SI, Sousa MC. Crystal structure of BamD: an essential component of the beta-Barrel assembly machinery of gram-negative bacteria. J Mol Biol. 2011;409:348-57.

77. Albrecht R, Zeth K. Structural basis of outer membrane protein biogenesis in bacteria. J Biol Chem. 2011;286:27792-803.

78. Onufryk C, Crouch ML, Fang FC, Gross CA. Characterization of Six Lipoproteins in the sigmaE Regulon. The Journal of Bacteriology. 2005;187:4552-61.

79. Ruiz N, Falcone B, Kahne D, Silhavy TJ. Chemical conditionality: a genetic strategy to probe organelle assembly. Cell. 2005;121:307-17.

80. Kim KH, Paetzel M. Crystal structure of Escherichia coli BamB, a lipoprotein component of the beta-barrel assembly machinery complex. J Mol Biol. 2011;406:667-78

81. Malinverni JC, Werner J, Kim S, Sklar JG, Kahne D, Misra R, et al. YfiO stabilizes the YaeT complex and is essential for outer membrane protein assembly in Escherichia coli. Mol Microbiol. 2006;61:151-64.

82. Nikaido H, Normark S. Sensitivity of Escherichia coli to various beta-lactams is determined by the interplay of outer membrane permeability and degradation by periplasmic beta-lactamases: a quantitative predictive treatment. Mol Microbiol. 1987;1:29-36.

83. Leive L, Telesetsky S, Coleman Jr WG, Carr D. Tetracyclines of various hydrophobicities as a probe for permeability of Escherichia coli outer membranes. Antimicrob Agents Chemother. 1984;25:539-44.

84. Eggers CH, Caimano MJ, Clawson ML, Miller WG, Samuels DS, Radolf JD Identification of loci critical for replication and compatibility of a Borrelia burgdorferi cp32 plasmid and use of a cp32-based shuttle vector for the expression of fluorescent reporters in the Lyme disease spirochaete. Mol Microbiol. 2002:43:281-95.

85. Gilbert MA, Morton EA, Bundle SF, Samuels DS. Artificial regulation of ospC expression in Borrelia burgdorferi. Mol Microbiol. 2007;63:1259-73.

86. Kawabata H, Norris SJ, Watanabe H. BBE02 disruption mutants of Borrelia burgdorferi B31 have a highly transformable, infectious phenotype. Infect Immun. 2004;72:7147-54

87. Stewart $P$, Thalken $R$, Bono J, Rosa P. Isolation of a circular plasmid region sufficient for autonomous replication and transformation of infectious Borrelia burgdorferi. Mol Microbiol. 2001;39:714-21.

88. Guex N, Peitsch MC. SWISS-MODEL and the Swiss-PdbViewer: an environment for comparative protein modeling. Electrophoresis. 1997;18:2714-23.

89. Luthra A, Zhu G, Desrosiers DC, Eggers CH, Mulay V, Anand A, et al. The transition from closed to open conformation of Treponema pallidum outer membrane-associated lipoprotein TP0453 involves membrane sensing and integration by two amphipathic helices. J Biol Chem. 2011;286:41656-68.

90. Kenedy MR, Luthra A, Anand A, Dunn JP, Radolf JD, Akins DR. Structural modeling and physicochemical characterization provide evidence that P66 forms a b-barrel in the Borrelia burgdorferi outer membrane. J Bacteriol. 2014;196:859-72

91. Frank KL, Bundle SF, Kresge ME, Eggers $\mathrm{CH}$, Samuels DS. aadA confers streptomycin resistance in Borrelia burgdorferi. J Bacteriol. 2003;185:6723-7.

92. Elias AF, Stewart PE, Grimm D, Caimano MJ, Eggers CH, Tilly K, et al. Clonal polymorphism of Borrelia burgdorferi strain B31 Ml: implications for mutagenesis in an infectious strain background. Infect Immun. 2002;70:2139-50.

93. Brooks CS, Vuppala SR, Jett AM, Alitalo A, Meri S, Akins DR. Complement regulator-acquiring surface protein 1 imparts resistance to human serum in Borrelia burgdorferi. J Immunol. 2005;175:3299-308.

94. Hunfeld KP, Kraiczy P, Wichelhaus TA, Schafer V, Brade V. New colorimetric microdilution method for in vitro susceptibility testing of Borrelia burgdorferi against antimicrobial substances. Eur J Clin Microbiol Infect Dis. 2000;19:27-32.

95. Skare JT, Shang ES, Foley DM, Blanco DR, Champion Cl, Mirzabekov T, et al. Virulent strain associated outer membrane proteins of Borrelia burgdorferi. J Clin Invest. 1995;96:2380-92.

96. Mulay V, Caimano M, Liveris D, Desrosiers DC, Radolf JD, Schwartz I. Borrelia burgdorferi BBA74, a Periplasmic Protein Associated with the Outer Membrane, Lacks Porin-Like Properties. The Journal of Bacteriology. 2007;189:2063-8.

97. Kenedy MR, Vuppala SR, Siegel C, Kraiczy P, Akins DR. CspA-mediated binding of human factor $\mathrm{H}$ inhibits complement deposition and confers serum resistance in Borrelia burgdorferi. Infect Immun. 2009;77:2773-82.

98. Nowalk AJ, Gilmore Jr RD, Carroll JA. Serologic proteome analysis of Borrelia burgdorferi membrane-associated proteins. Infect Immun. 2006;74:3864-73.

\section{Submit your next manuscript to BioMed Central and take full advantage of:}

- Convenient online submission

- Thorough peer review

- No space constraints or color figure charges

- Immediate publication on acceptance

- Inclusion in PubMed, CAS, Scopus and Google Scholar

- Research which is freely available for redistribution 